\title{
Occlusion of Common Iliac Artery as an Unexpected Complication Following Angioplasty via Retrograde Popliteal Access: A Case Report
}

\author{
Anjioplasti Sonrası Ana İliak Arterde Meydana Gelen Beklenmedik \\ Okluzyonun Retrograd Popliteal Yaklaşımla Tedavisi: Vaka Sunumu
}

\author{
@Ömer Faruk Çiçek', @Kerim Esenboğa ${ }^{2}$ \\ 'Department of Cardiovascular Surgery, Selçuk University Medical Faculty, Konya, Turkey \\ 2Department of Cardiology, Ankara University Medical Faculty, Ankara, Turkey
}

\begin{abstract}
Treatment of the lesions located in the popliteal artery and superficial femoral artery are potentially clinical challenge because of the long length of lesions, high- calcium content in the vessel wall and inside the plaques, and individual dynamic forces found within these vessels. Intraluminal or subintimal recanalization of the vessel lumen is achieved mostly by ipsilateral antegrade or contralateral retrograde femoral approach in the treatment of total occlusion of the superficial femoral artery. In the event of failure, retrograde access into the popliteal artery is considered as an essentially different method. In our case report, we aimed to present rescue retrograde popliteal intervention following an unsuccessful antegrade approach which resulted in an unexpected atherothrombotic complication that occurred in the common iliac artery of the contralateral side.
\end{abstract}

Keywords: Atherothrombosis, peripheral arterial disease, retrograde popliteal intervention

\section{INTRODUCTION}

The worldwide prevalence of peripheral artery disease (PAD), an important cause of cardiovascular morbidity and mortality, is between 3 to $10 \%{ }^{[1]}$ The aim of the management of patients with PAD is relieving symptoms and lowering the risk of cardiovascular disease progression and complications. For patients with disabling symptoms resistant to lifestyle modification and pharmacologic
Öz

Yüzeyel femoral ve popliteal arterlerdeki ciddi lezyonların tedavisinde lezyonların uzunluğu, lokalizasyonu ve plak yapısındaki ya da damar duvarındaki yüksek kalsiyum içeriği nedeniyle uygulanacak strateji her vakada bireysel farklılık göstermektedir. Yüzeyel femoral arter okluzyonlarının tedavisinde ipsilateral antegrad ya da kontralateral retrograd yaklaşım sık kullanılmakla birlikte özellikle bu tedavi seçeneklerinin başarılı olmadığı durumlarda retrograd popliteal girişim de alternatif olarak kullanılabilmektedir. Bu vaka sunumunda, antegrad yaklaşımın başarısız olması üzerine popliteal arter yoluyla retrograd yaklaşımın başarılı bir şekilde uygulandığı ancak işlem sonrası karşı taraf ana iliak arterde gerçekleşen beklenmedik aterotrombotik komplikasyon ve başarılı çözümü takdim edilmiştir.

Anahtar Kelimeler: Aterotromboz, periferik arter hastalığı, retrograd popliteal girişim therapy, intervention (percutaneous, surgical) is reasonable. One of the most common vessels involved in symptomatic lower limb atherosclerosis is superficial femoral artery (SFA). Treatment of the lesions located in the popliteal artery (PA) and SFA are potentially clinical challenge because of the long length of lesions and high calcium content in the vessel wall and inside the plaques. 
Intraluminal or subintimal recanalization of the vessel lumen is achieved mostly by the ipsilateral antegrade or contralateral retrograde femoral approach in the treatment of total occlusion of the superficial femoral artery. In the event of failure, retrograde popliteal access (RPA) is considered as an essential alternative method. Initially, the RPA was used as a backup option since there were some limitation factors. ${ }^{[2]}$ However, refinements to this method have made this option an attractive alternative technique. ${ }^{[3]}$

In this case report, we aimed to present a successful retrograde approach through the PA following an antegrade approach that failed due to the inability to enter the distal true lumen. We also drew attention to the unexpected atherothrombotic complication that occurred in the common iliac artery of the contralateral side after the retrograde approach in our case.

\section{CASE REPORT}

A 51-year-old man presented to our outpatient clinic for left leg pain with a maximal walking distance of 150 meters. Patient's Society for Vascular Surgery Lower Extremity Threatened Limb (SVS WIfI) classification for right lower extremity was wound 0 , ischemia 1 , foot infection 0 , which corresponded to stage 1 and for left lower extremity was wound 0 , ischemia 2, foot infection 0 , which corresponded to stage $2 .{ }^{[4]}$ The patient was under appropriate medical treatment involving acetylsalicylic acid, perindopril, metoprolol, cilostazol, and atorvastatin. We have learned from the past medical history of the patient that he has been followed for the last six months due to peripheral arterial disease and that his complaints have increased in the last 3 months despite medical treatment and exercise therapy. Color Doppler ultrasound examination revealed that the peripheral arterial pathology by demonstrating the monophasic flow pattern with increased acceleration time indicating proximally severe stenosis in all arterial structures in left lower limb and preserved biphasic circulation in right lower extremity. The ankle-brachial index was 0.38 on the left side with non-palpable pedal pulses and 0.63 on the right side with palpable dorsalis pedis and posterior tibial artery pulses. He had coronary artery bypass surgery 5 years ago and his comorbidities included uncontrolled diabetes mellitus, current smoking, hypertension, and a recent non-ST segment elevation myocardial infarction in which coronary angiography revealed distal vessel disease with open bypass grafts. The patient's body mass index was $22.6 \mathrm{~kg} / \mathrm{m}^{2}$ without a distinct pulmonary disease. Additionally, the patient had chronic kidney disease due to resistant hypertension with a creatinine level of $1.5 \mathrm{mg} / \mathrm{dl}$. His left ventricular function was normal (ejection fraction $=60 \%$ ) without any regional wall motion abnormality and clinically important valve pathology.

Peripheral angiography performed through the right common femoralaccess demonstrated a totalocclusion in approximately $15 \mathrm{~cm}$ segment in left SFA with the reconstitution of the PA and the distal SFA, and bilateral severe stenosis in common iliac arteries (Figure 1A-1C). Percutaneous intervention was decided to be performed due to disabling symptoms resistant to lifestyle modification and medical treatment. $A$ 7 Fr peripheral guiding sheath (Destination ${ }^{\circledR}$; Terumo, Tokyo) was inserted into the left common iliac artery (LCIA), and an angled 0.035-inch hydrophilic guidewire (Radifocus; Terumo Corporation, Tokyo, Japan) with a microcatheter support was used to pass the totally occluded segment in left SFA. After placement of the long sheath 7000 units of unfractionated heparin was administered intravenously. Unfortunately, the total occlusion in SFA was blunt-ended and adjacent to a large side branch that prevented the guidewire to enter the occluded segment. Since the distal SFA and PA were normal in caliber and do not have severe stenotic lesions, a retrograde approach via the left PA was thought as an alternative option. We obtained the roadmap of the arteries by injecting the contrast from LCIA in an antegrade direction to perform a retrograde approach via the PA. The PA was then punctured at approximately 4-5 cm above the knee joint with a Terumo radial sheath seldinger needle by the guidance of roadmap fluoroscopy in the prone position. A 0.035 -inch guidewire was advanced to the distal part of SFA after a successful puncture, and an angiogram was performed after $6 \mathrm{Fr}$ radial sheath insertion to confirm that the PA access was accomplished

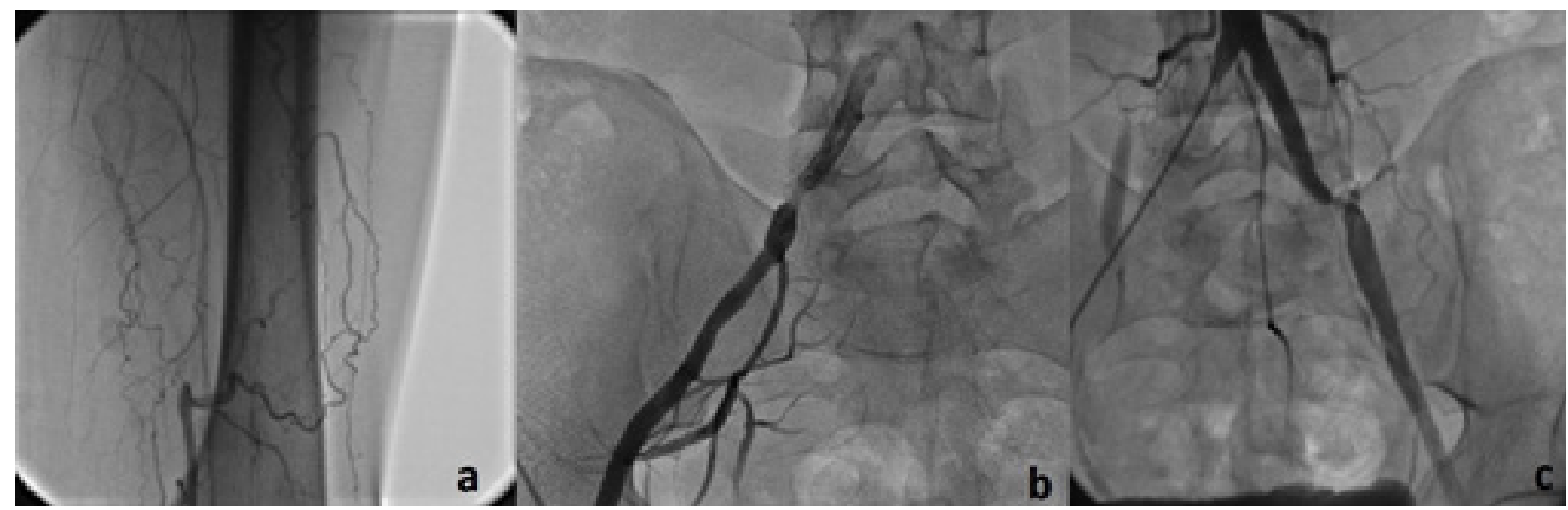

Figure 1. Angiographic image of total occlusion in left SFA (A), severe stenosis in right (B) and left (C) common iliac arteries. 
properly. After passing the retrograde wire into the true lumen of the left common femoral artery (CFA) successfully, a $6.0 \times 120 \mathrm{~mm}$ drug-coated balloon was used for dilatation of the total occluded segment (Figure 2). The guidewire could be successfully passed through the severe lesion located in the LCIA, and a balloon-expandable cobalt-chromium stent (RESTORER $8 \times 58 \mathrm{~mm}$; iVascular, Barcelona, Spain) were placed here. No hemostatic tool other than a sponge and manual compression was used for complete hemostasis after removal of the sheath from the PA, and complications related to access site were not observed. The total duration of our procedure was approximately 3 hours. During the procedure, the activated clotting time (ACT) value was checked with an interval of half an hour. Additional heparin was administered if the ACT value was found to be lower than 300 seconds. A total volume of 350 cc contrast media was used.

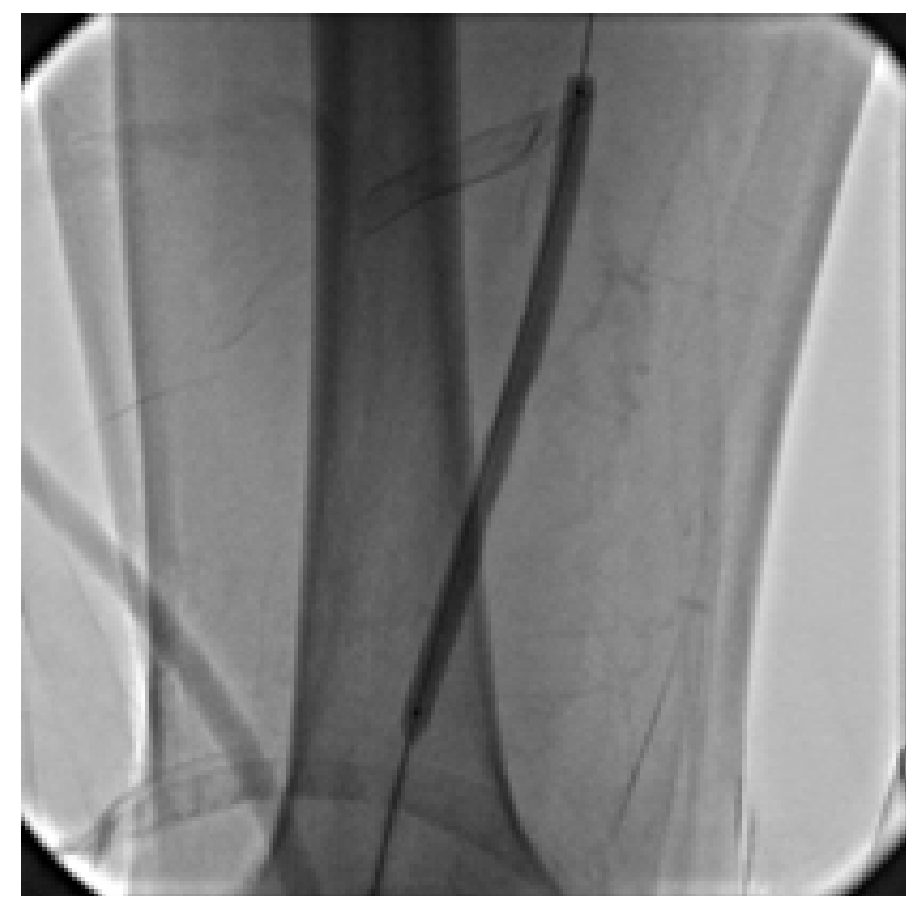

Figure 2. Angiographic image of percutaneous transluminal angioplasty with drug coated balloon for the total occlusion in the left SFA.

Following the procedure, it was decided to postpone the intervention to right common iliac artery ( $\mathrm{RCIA}$ ) not only to avoid contrast nephropathy but also the time of procedure was too long. Two days after the procedure the patient was taken to the catheter laboratory again for planned intervention to $\mathrm{RCIA}$. After performing the angiography, a total occlusion in a severely diseased segment in the RCIA was observed unexpectedly (Figure 3 ). Interestingly, the patient did not have any complaints during this time. A 0.035-inch guidewire was advanced to the abdominal aorta by passing the totally occluded segment in RCIA and following the dilation with $5.0 \times 60 \mathrm{~mm}$ balloon, a balloon-expandable cobalt-chromium stent (RESTORER 7.0×58 mm; iVascular, Barcelona, Spain) were placed here which yielded a satisfactory final result (Figure 4A, 4B). The period after interventions was uneventful and the patient was discharged home 3 days after the second procedure. Written informed consent was obtained from the patient who participated in this study.

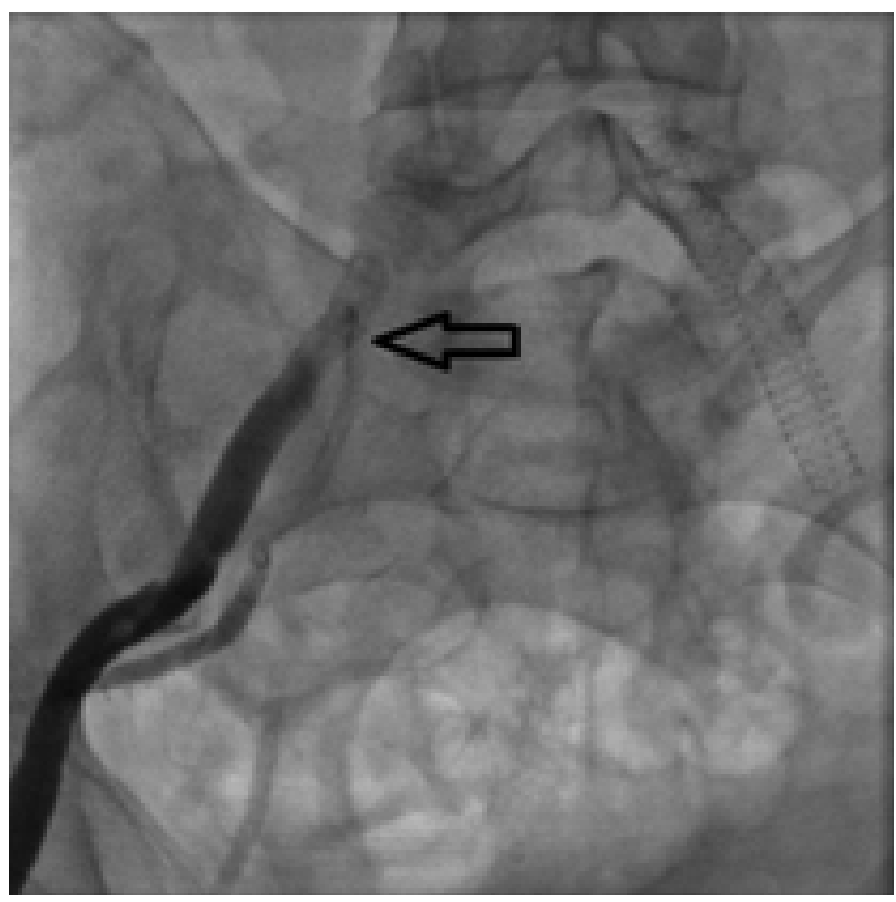

Figure 3. Newly formed total occlusion (arrow) in severely diseased segment in the RCIA.

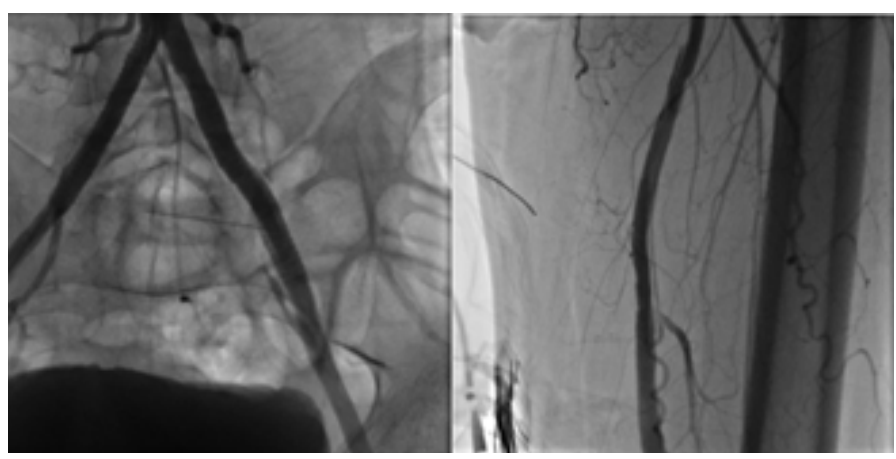

Figure 4. Final result of successful revascularization of bilateral common iliac arteries (A) and left SFA (B).

\section{DISCUSSION}

The development of endovascular treatments and the innovations in various endovascular instruments and methods have overcome many of the previous anatomic obstacles that restricted their safe and frequent use. Alternatives of arterial access for SFA lesions, inter alia, currently make easier this complicated percutaneous transluminal angioplasty if considered as inaccessible. The unique features of the SFA complicate the revascularization procedure either requiring the retrograde contralateral or the antegrade ipsilateral CFA approach. ${ }^{[2,5]}$ The contralateral approach can be so difficult 
in patients whose angle of aortic bifurcation is so narrow and is not possible in patients formerly had treatment for an aneurysm of the abdominal aorta. Additionally, long introducers and instruments are needed, and pushability of these devices is not enough. Although the ipsilateral femoral approach provides better advance ability due to the use of short devices, this technique is not easy to use in obese patients. In addition, it is not possible to use if there are severe stenotic lesions affecting the CFA, and furthermore, it may be very complicated when there is a diseased segment in the proximal SFA. Transradial or trans-axillary approaches are also alternative methods. Blunt lesions in SFA and the emergence of a large side branch or collateral from the side of the total occlusion hinder these approaches, as well as one of the most important limiting factor, is the fact that the devices used must be quite long. The contralateral (crossover) and antegrade femoral approaches have been well established, however, the retrograde PA approach is still considered as a conceivably efficacious option for the endovascular intervention of infra-inguinal severe arterial stenotic lesions in patients that antegrade procedures are unavailable. ${ }^{[6]}$

Tandem SFA/CFA lesions and antegrade approach failure are the major indications for RPA..$^{[2,3]}$ It has been claimed that passing through the lesion may be more advantageous, given the less severely calcified or fibrotic plaque formation by approaching from the distal end. ${ }^{[2,3,5]}$ Possible complications of the RPA method involve iliac-femoral dissection, arteriovenous fistula, distal embolization, PA occlusion at the access site, and hematomas. But recent studies demonstrated that frequencies of major complications are low. ${ }^{[7]}$ In our case, we had no vascular complications. After antegrade approach failure, usually, it is not easy for a patient to turn to prone position from supine position. This causes an increase in the patient's distress and this position is uncomfortable, especially for those who were overweight and had poor respiratory function. In our case, our patient's body mass index was normal in range and respiratory status was good, so proceeding with the procedure in the prone position did not constitute a problem for the patient and the operator.

The risk of puncture of both vessels by the needle is so high, because the PA is located just anterior to the vein, so the most probable vascular complication in RPA is an arteriovenous fistula. On the other hand, performing puncture by ultrasound guidance to refrain from fistula formation can essentially ensure real-time imaging of the vessels and the needle. As the operator visually checks the needle, the vein, and the PA, the risk of perforation of the vein is low, and consequently, the possibility of fistula formation is limited as well. In a series of 234 cases by Yilmaz et al. ${ }^{[7]}$ no arteriovenous fistula was observed. Albeit ultrasound guidance is safer compared to roadmap in terms of having the advantage of visualizing the vein to avoid an accidental puncture, safe PA puncture can also be accomplished using the roadmap technique. In our case since we did not have an ultrasound, so the roadmap method was used.
In this case report, the retrograde approach was used successfully for revascularization of severely diseased LCIA and totally occluded SFA, but unexpectedly a total occlusion was observed in the contralateral side possibly due to plaque rupture or erosion with a silent clinic. It should be kept in mind that in such similar cases with long procedural time, some unexpected atherothrombotic events in different regions, except for lesion zones can occur by different pathophysiological mechanisms. Although plaque structure does not appear to be ulcerative or thrombotic in the baseline, it is suggested that we should pay more attention to followup of atherothrombotic complications after such a prolonged procedure.

\section{ETHICAL CONSIDERATIONS}

Informed Consent: Written informed consent was obtained from all participants who participated in this study.

Status of Peer-review: Externally peer-reviewed.

Conflict of Interest Statement: The authors have no conflicts of interest to declare.

Financial Disclosure: The authors declared that this study has received no financial support.

Author Contributions: All of the authors declare that they have all participated in the design, execution, and analysis of the paper, and that they have approved the final version.

\section{REFERENCES}

1. Norgren L, Hiatt WR, Dormandy JA, et al. Inter-Society Consensus for the Management of Peripheral Arterial Disease (TASC II). J Vasc Surg 2007;45 Suppl S:S5-67.

2. Fanelli F, Lucatelli $P$, Allegritti M, et al. Retrograde popliteal access in the supine patient for recanalization of the superficial femoral artery: initial results. J Endovasc Ther 2011;18(4):503-9.

3. Brountzos EN, Moulakakis KG, Avgerinos ED, et al. Retrograde transpopliteal approach of iliofemoral lesions. Vasc Endovascular Surg 2011;45(7):646-50.

4. Darling JD, McCallum JC, Soden PA, et al. Predictive ability of the Society for Vascular Surgery Wound, Ischemia, and foot Infection (WIfI) classification system following infrapopliteal endovascular interventions for critical limb ischemia. J Vasc Surg 2016;64(3):616-22.

5. Schmidt A, Bausback $Y$, Piorkowski $M$, et al. Retrograde recanalization technique for use after failed antegrade angioplasty in chronic femoral artery occlusions. J Endovasc Ther 2012;19(1):23-9.

6. Heenan SD, Vinnicombe SJ, Buckenham TM, et al. Percutaneous transluminal angioplasty by a retrograde subintimal transpopliteal approach. Clin Radiol 1994;49(11):824-7; discussion 827-8.

7. Yilmaz S, Sindel T, Luleci E. Ultrasound-guided retrograde popliteal artery catheterization: experience in 174 consecutive patients. J Endovasc Ther 2005;12(6):714-22. 